\title{
Analysis of Carbon Emissions of Logistics Industry in Tianjin Based on Environmental Kuznets Model
}

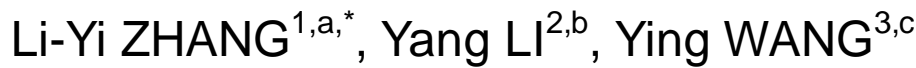

${ }^{1}$ School of Electronic Information Engineering, Tianjin University of Commerce, Tianjin, P.R. China

${ }^{2}$ School of Economics, Tianjin University of Commerce, Tianjin, P.R. China

${ }^{3}$ School of Economics, Tianjin University of Commerce, Tianjin, P.R. China

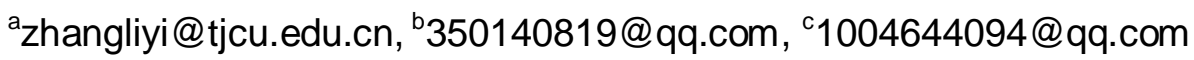

${ }^{*}$ Corresponding author

Keywords: Logistics industry, Carbon emissions, EKC model.

\begin{abstract}
The logistics industry is one of the major industries involving carbon emissions. It is significant for energy-conservation and emissions-reduction to study the relationship between development of logistics and carbon emissions. This paper estimates the statistics of carbon emissions about logistics industry based on energy-consumption from 1995 to 2011 in Tianjin area. And then, time-series data relating to output value of logistics industry and the carbon emissions is fitted. This paper analyzes the situation of carbon emissions according to the result of regression analysis and EKC model. At last, low carbonization strategy is proposed according to local logistics industry status.
\end{abstract}

\section{Introduction}

In recent years, development of low carbon economy has become the hot spot of government and scholars, as a result of the serious effects on people's life for global warming and environmental pollution. At present, greenhouse gas emissions of China runs up to $15 \%$ of this of whole world every year, while $\mathrm{CO}_{2}$ is accounting for more than $80 \%$ of greenhouse gas. The average annual growth rate of $\mathrm{CO}_{2}$ emissions is $17.8 \%$, which was leaped into the front ranks of the world in past 10 years [1]. According to the people's republic of China national economic and social development in the twelfth five year plan outline in March $2011, \mathrm{CO}_{2}$ emissions per unit of GDP in 2015 should decline by $17 \%$ compared to 2010 . China is still facing great pressure on $\mathrm{CO}_{2}$ reduction to achieve this goal.

In addition to large energy consumption, the logistics industry cause huge carbon emissions. The transportation accounts for around $25 \%$ of global $\mathrm{CO}_{2}$ emissions, suggested by report titled transport, energy and carbon dioxide: towards sustainable development released by IEA in 2009 [2]. The oil consumption of China's logistics industry ranks only after manufacturing industry, and the high greenhouse gas emission due to oil makes the logistics industry become the hot spot of energy conservation and emissions reduction [3]. Therefore, the low carbon development of logistics industry is an important way to realize the low carbon economy.

Tianjin has stated its propositions clearly in Tianjin city national economic and social development in the twelfth five year plan that it is important to speed up the establishment of the position of international shipping center and international logistics center in northern area. With the rapid development of logistics industry in recent years, the annual growth rate of logistics industry remained at more than $20 \%$. At the same time, as one of the national low carbon city pilot units, it possesses positive guidance for Tianjin to explore and study the development of low carbon logistics industry.

\section{Estimation about Carbon Emission of Tianjin's Logistics Industry}

\section{Data Sources}

The data about various energy consumption from 1995 to 2011 in Tianjin of this paper is refers to 
China energy statistical yearbook. The folding of standard coal coefficient of various energy come from China energy statistical yearbook in 2012, and the carbon emission coefficient of various energy come from national development and reform commission's inform about recommending national key energy-saving technology developed by organization .

\section{Estimation Method}

Since there is no direct monitoring data of $\mathrm{CO}_{2}$ emissions of logistics industry currently, information of carbon emissions is estimated. The $\mathrm{CO}_{2}$ emissions are mainly from combustion of fossil fuel, so we can estimate the $\mathrm{CO}_{2}$ emissions of logistics industry according to consumption of various energy of logistics industry. Estimation formula is:

$$
C=\sum_{i=1}^{3} C_{i}=\sum_{i=1}^{3} E_{i} \theta_{i} \delta_{\mathrm{i}}
$$

where $C$ is total carbon emissions, $C_{i}$ is carbon emissions of energy, $E_{i}$ is energy consumption, $\theta_{i}$ is folding of standard coal coefficient and $\delta_{i}$ is carbon emission coefficient. There are some common various energy folding of standard coal coefficient and various energy carbon emission coefficient shown in table 1 and table 2.

Table 1Various energy folding of standard coal coefficient

\begin{tabular}{|c|c|c|c|}
\hline Types of energy & Raw coal & Crude oil & Electric power[kW $\cdot \mathrm{h}]$ \\
\hline $\begin{array}{c}\text { Folding of standard } \\
\text { coal coefficient }\end{array}$ & 0.7143 & 1.4286 & 0.1229 \\
\hline
\end{tabular}

Data sources: China energy statistical yearbook

Table 2 Various energy Carbon emission coefficient

\begin{tabular}{|c|c|c|c|}
\hline Types of energy & Coal & Oil & Electric power \\
\hline $\begin{array}{c}\text { t carbon } / \mathrm{t} \text { standard } \\
\text { coal }\end{array}$ & 0.7200 & 0.5673 & 0.5844 \\
\hline
\end{tabular}

Data sources: national development and reform commission's inform about recommending national key energy-saving technology developed by organization.

\section{Estimation and Trend of Total Carbon Emissions' Change}

We can get the consumption of various energy of logistics industry from 1995 to 2011 in Tianjin according to China energy statistical yearbook, and based on formula (1), carbon emissions of energy are shown in table 3. 
Table 3 Carbon emissions of logistics industry in Tianjin [Unit: Ten thousand tons]

\begin{tabular}{|c|c|c|c|c|c|c|c|c|}
\hline \multirow[b]{2}{*}{ Years } & \multirow{2}{*}{$\begin{array}{l}\text { Outpu } \\
\mathrm{t} \\
\text { value } \\
\text { of } \\
\text { logisti } \\
\text { cs } \\
\text { indust } \\
\text { ry } \\
\text { [One } \\
\text { hundr } \\
\text { ed } \\
\text { millio } \\
n \\
\text { yuan] }\end{array}$} & \multicolumn{2}{|c|}{ Coal } & \multicolumn{2}{|l|}{ Oil } & \multicolumn{2}{|c|}{ Electric power } & \multirow[b]{2}{*}{$\begin{array}{c}\text { Total } \\
\text { carbon } \\
\text { emissio } \\
\text { ns }\end{array}$} \\
\hline & & $\begin{array}{c}\text { Consump } \\
\text { tion [Ten } \\
\text { thousand } \\
\text { tons of } \\
\text { standard } \\
\text { coal] }\end{array}$ & $\begin{array}{c}\text { Equivalent } \\
\text { carbon } \\
\text { emissions }\end{array}$ & $\begin{array}{c}\text { Consumption } \\
\text { [Ten thousand } \\
\text { tons of } \\
\text { standard coal] }\end{array}$ & $\begin{array}{c}\text { Equivale } \\
n t \\
\text { carbon } \\
\text { emission } \\
\mathrm{s}\end{array}$ & $\begin{array}{l}\text { Consumption } \\
\text { [Ten } \\
\text { thousand tons } \\
\text { of standard } \\
\text { coal] }\end{array}$ & $\begin{array}{c}\text { Equivale } \\
n t \\
\text { carbon } \\
\text { emission } \\
\mathrm{s}\end{array}$ & \\
\hline 1995 & 86.85 & 18.06 & 13.00 & 68.42 & 38.81 & 3.59 & 2.10 & 53.91 \\
\hline 1996 & 92.08 & 13.81 & 9.94 & 105.07 & 59.60 & 3.44 & 2.01 & 71.55 \\
\hline 1997 & 102.92 & 13.41 & 9.66 & 125.40 & 71.14 & 6.18 & 3.61 & 84.41 \\
\hline 1998 & 121.48 & 12.79 & 9.21 & 156.20 & 88.61 & 4.28 & 2.50 & 100.32 \\
\hline 1999 & 144.22 & 13.24 & 9.53 & 152.05 & 86.26 & 4.47 & 2.61 & 98.40 \\
\hline 2000 & 162.75 & 15.04 & 10.83 & 204.20 & 115.84 & 5.24 & 3.06 & 129.73 \\
\hline 2001 & 184.17 & 17.52 & 12.61 & 205.56 & 116.61 & 5.59 & 3.27 & 132.49 \\
\hline 2002 & 210.03 & 15.02 & 10.81 & 225.76 & 128.07 & 6.00 & 3.50 & 142.38 \\
\hline 2003 & 173.57 & 28.89 & 20.80 & 272.96 & 154.85 & 17.29 & 10.11 & 185.76 \\
\hline 2004 & 245.89 & 15.73 & 11.33 & 291.88 & 165.58 & 8.26 & 4.83 & 181.74 \\
\hline 2005 & 194.32 & 15.48 & 11.15 & 292.03 & 165.67 & 8.01 & 4.68 & 181.50 \\
\hline 2006 & 213.24 & 12.41 & 8.94 & 305.45 & 173.28 & 8.48 & 4.96 & 187.18 \\
\hline 2007 & 236.38 & 11.06 & 7.96 & 300.99 & 170.75 & 11.49 & 6.72 & 185.43 \\
\hline 2008 & 243.45 & 13.51 & 9.73 & 335.64 & 190.41 & 13.61 & 7.95 & 208.09 \\
\hline 2009 & 360.10 & 13.97 & 10.06 & 361.72 & 205.20 & 15.46 & 9.04 & 224.30 \\
\hline 2010 & 433.29 & 21.96 & 15.81 & 385.31 & 218.59 & 19.43 & 11.36 & 245.76 \\
\hline 2011 & 443.89 & 20.29 & 14.61 & 409.98 & 232.58 & 21.95 & 12.83 & 260.02 \\
\hline
\end{tabular}

As can be seen from the data in the table, from 1995 to 2011, the carbon emissions of logistics industry in Tianjin showed a upward tendency as a whole. In this 17 years, the carbon emissions increase from 539.1 thousand tons to 2600.2 thousand tons, increased by $382.32 \%$, and the average annual growth rated up to $10.33 \%$. And in 1996, the growth rate is fastest, reached $32.72 \%$.

Viewed from the carbon emissions of different energy, the trend of coal's carbon emissions is complex, showing a "W" type, while there is a general uptrend in the carbon emissions of oil and electric power. Specifically, carbon emissions of coal fluctuated from 79.6 thousand tons to 208.0 thousand tons, reached the bottom in 1998 and 2007, respectively 92.1 thousand tons and 79.6 thousand tons, and reached its peak in 2003, up to 208.0 thousand tons. The carbon emissions of oil increased from 388.1 thousand tons to 2325.8 thousand tons, increased by $499.28 \%$, and the average annual growth rated up to $11.84 \%$, and in 1996 the growth rate is fastest, reached $53.57 \%$. The carbon emissions of electric power increase from 21.0 thousand tons to 128.3 thousand tons, increased by $510.96 \%$, and the average annual growth rate up to $11.98 \%$, and in 2003 the growth rate was fastest, reached $188.86 \%$. At the same time, we can see that carbon emissions of oil had been higher than that of other energy.

\section{Analysis of Carbon Emission of Tianjin Logistics Industry Based on EKC Model}

In the 1950s, studying the relationship between income levels and distributive justice, Simon 
Kuznets [4] found a phenomenon of income inequality. This phenomenon increased at first and then decreased, shows inverted U curve, which is the Kuznets curve. Then, scholars found that there was also inverted $U$ curve between environmental pollution and economic development level. So the environmental Kuznets curve (EKC) EKC was extended according to the Kuznets curve. In recent years, scholars found that the EKC model shows not only inverted $\mathrm{U}$ type, but also $\mathrm{U}$ type, $\mathrm{N}$ type and even linear relation [5]. The mathematical model is that

$$
y=b_{0}+b_{1} x+b_{2} x^{2}+b_{3} x^{3} .
$$

When $b 1 \neq 0$ and $b 2=b 3=0$, it fits linear relation. When $b 1>0, b 2<0$ and $b 3=0$, it fits inverted $U$ type. When $b 1<0, b 2>0$ and $b 3=0$, it fits $U$ type. When $b 1>0, b 2<0$ and $b 3>0$, it fits $\mathrm{N}$ type. When $\mathrm{b} 1<0, \mathrm{~b} 2>0$ and $\mathrm{b} 3<0$, it fits inverted $\mathrm{N}$ type.

In this paper, carbon emissions are defined as the dependent variables $y$, and logistics industry output as the independent variable $\mathrm{x}$. The logistics industry output and carbon emissions of Tianjin are analyzed by linear, quadratic and cubic curve fitting, based on SPSS19.0. The curves are shown in Figure 1, and we can find parameters in Table 4. In order to eliminate the price factor, we convert the logistics industry output into the constant prices that base period is 1995.

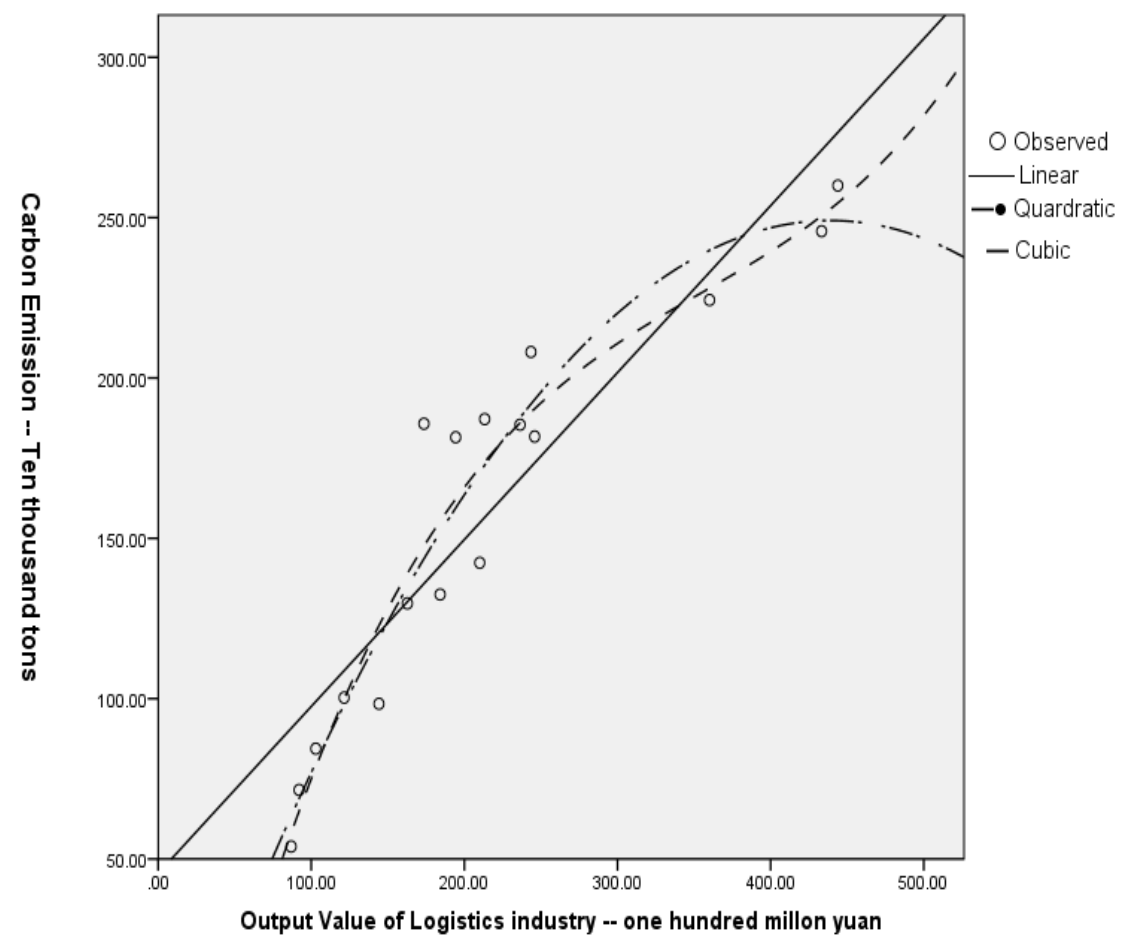

Figure 1 The curve fitting chart

Table 4 Estimates of the model parameters

\begin{tabular}{|c|c|c|c|c|c|c|c|c|}
\hline \multirow{2}{*}{ Equation } & \multicolumn{4}{|c|}{ Model summary } & \multicolumn{4}{c|}{ Parameter estimates } \\
\cline { 2 - 10 } & $\begin{array}{c}\text { Adjusted } \\
\mathrm{R}^{2}\end{array}$ & $\begin{array}{c}\text { Estimate } \\
\text { of standard } \\
\text { deviation }\end{array}$ & $\mathrm{F}$ & Sig. & $\mathrm{b}_{0}$ & $\mathrm{~b}_{1}$ & $\mathrm{~b}_{2}$ & $\mathrm{~b}_{3}$ \\
\hline linear & 0.822 & 25.972 & 75.123 & 0.000 & 45.513 & 0.521 & & \\
\hline quadratic & 0.906 & 18.871 & 78.358 & 0.000 & -39.598 & 1.316 & -0.001 & \\
\hline cubic & 0.905 & 18.966 & 52.003 & 0.000 & -91.927 & 2.149 & -0.005 & $4.985 \mathrm{E}-6$ \\
\hline
\end{tabular}

Adjustment of the $\mathrm{R}^{2}$ is adjusting coefficient of determination. It is a metrics by synthetically measuring the goodness of fitting regression model with sample observations. And the greater the 
value, the higher the fitting precision is. The standard deviation of estimates is used to illustrate the relative deviation degree index between actual value and estimates. And the smaller the standard deviation of estimates, the greater practicality the regression equation has. Sig. is the probability of F of model, reflecting the significant level of model. If Sig. $<0.05$, the difference is remarkable and equation is significance. From the table, we can see the Sig. values of three models are less than 0.05 , which means that all the models are statistical significance. Contrast adjustment $\mathrm{R}^{2}$ with standard deviation, we can find $\mathrm{R}^{2}$ of quadratic model is 0.906 which is bigger than linear and cubic model. At the same time, the quadratic model has the smallest standard deviation which is 18.871 , so it is the best fitting. According to the above table, the regression equation is that

$$
y=-39.598+1.316 x-0.001 x^{2} .
$$

According to regression equation and fitting curves, the relationship between logistics development and carbon emissions of Tianjin shows inverted U curve. Namely, with the increase of logistics industry output, carbon emissions increased at first and then decreased. At present, logistics industry of Tianjin is still in the process. And the carbon emissions are still increasing, but growth rate is slowing down. Based on EKC model, the relationship between logistics development and carbon emissions in Tianjin is still in the left half of EKC, but it will reach the inflection point soon.

\section{Conclusion}

Based on the above analysis, we can draw the following conclusions. First, the carbon emissions of logistics industry in Tianjin are mainly caused by the oil consumption. As can be seen from the data in Table 3, since 1996, the carbon emissions come from oil consumption in logistics industry accounts for more than $80 \%$ of total carbon emissions. Second, the relationship between logistics development and carbon emissions of Tianjin shows inverted $U$ curve, and it will reach the inflection point soon. And the development of low carbon logistics industry has made some progresses.

Therefore, to promote low carbon development of Tianjin, we should optimize the energy source composition; promote the use of clean energy at first. According to notice of Tianjin about low carbon city pilot implementation plan, Tianjin government put forward some plans. That are vigorously developing solar energy and utilization of geothermal energy, actively supporting and guiding photovoltaic power generation, wind power generation and biomass power generation and expanding the source and the field of application of natural gas, and by 2015, proportion of natural gas in the structure of primary energy should accounts for more than $8 \%$. Secondly, to achieve the purpose of energy saving we should speed up the construction of logistics information platform, allocate logistics resource intensively and optimally, realize multimodal transport modes such as railway transport, air transport and sea transport, and improve the rate of actual loading. Thirdly, we should also develop low carbon logistics operation standard, establish perfect assessment and the incentive and constraint mechanism of energy-saving emission reduction and guide the logistics enterprises to use information technology to reform the traditional logistics mode, to achieve low carbon logistics operation.

This work was supported by 2014 China Logistics Association research projects (No. 2014CSLKT3-176).

\section{References}

[1] X. Zhao, Y. Hu, Carbon market: systematic risk and expectations of returns, J. Journal of Beijing institute of technology. 1 (2013) 5-11. 
[2] U.S. Energy Information Administration, Transport, energy and $\mathrm{CO}_{2}$, moving towards sustainability, Washington, 2009.

[3] X. Duan, Y. Zhang, Research on development path to domestic low carbonated logistics based on principal component analysis, J.Science technology progress and Policy. 22 (2010) 96-99.

[4] S. Kuznets, Economic growth and income inequality, J. The American economic review. 1 (1955) $1-28$.

[5] Y. Han, Y. Lu, The relationship between economic growth and environmental quality:an empirical test on the environmental Kuznets curve of $\mathrm{CO}_{2}$, J. Economic theory and economic management. 3 (2009) 5-11. 